\title{
Microstructure and Segregation Behavior of Rene88DT Alloy Prepared by ESR-CDS
}

\author{
Li Fulin, Fu Rui, $\quad$ Feng Di, $\quad$ Yin Fajie, $\quad$ Tian Zhiling
}

High Temperature Materials Division, Central Iron and Steel Research Institute, Beijing 100081, China

\begin{abstract}
Directionally solidified Rene88DT alloy ingots were produced by electroslag remelting continuous directional solidification (ESR-CDS) technology. The as-cast structures of ESR-CDS Rene88DT alloy ingot were analyzed by optical microscopy (OM), field emission scanning electron microscopy (FESEM) with energy spectrum and transmission electron microscopy(TEM), and simultaneously compared with conventional ESR ingot. The results show that the region of the severe central segregation existing commonly in the conventional ESR ingot is eliminated in the ESR-CDS Rene88DT alloy ingot, because the above segregation is formed in the intersection of interfaces among columnar crystals and equiaxed crystals or between columnar crystals each other. In addition, the ESR-CDS Rene88DT alloy ingot shows smaller secondary dendritic spacing and smaller non-equilibrium precipitates phase. Due to the decreasing micro-segregation level, the uniform distribution of alloy elements can be achieved when Rene 88DT alloy is subjected to the heat treatment at $120{ }^{\circ} \mathrm{C}$ for $24 \mathrm{~h}$. Statistical results of inclusions reveal that the maximum size of inclusion in the ESR-CDS Rene88DT alloy is not more than $5.89 \mu \mathrm{m}$ and the inclusion volume reduces by over $60 \%$ compared with conventional ESR and P/M, respectively. The hot working plasticity of directionally solidified Rene88DT superalloy can be improved, which provides a basis for implementation of cast-and-wrought $(\mathrm{C} \& \mathrm{~W})$ route.
\end{abstract}

Key words: Rene88DT alloy; ESR-CDS; C\&W route; non-equilibrium precipitates; inclusion

Nickel-base superalloys display promising physical and mechanical properties, which have been widely used in fabrication of turbine disk as one of the most important components in gas advanced engines ${ }^{[1]}$. There are two distinct approaches available for the preparation of the superalloy billets, which include the conventional $\mathrm{C} \& \mathrm{~W}$ (cast and wrought) route and powder metallurgy (P/M) processing $^{[2]}$. The choice of processing route depends upon the alloying extent and the deformation resistance of the alloy. Alloys such as waspaloy and IN718 are generally prepared by ingot metallurgy, since the levels of strengthening elements $\mathrm{Al}, \mathrm{Ti}, \mathrm{W}$ and Mo are relatively low. Unfortunately, C\&W route can not be applied to the heavily alloyed refractory superalloys such as Rene $95^{[3]}$ and Rene $88 \mathrm{DT}^{[4]}$, since the high levels of segregation generated during solidification process cause the tendency to cracking during hot working; instead, $\mathrm{P} / \mathrm{W}$ route is preferred, despite the disadvantages of high cost, long process and difficulty of preparing powder without inclusions ${ }^{[5]}$.

The segregation characteristics of the ingot prepared by conventional cast-and-wrought $(\mathrm{C} \& \mathrm{~W})$ route are mainly displayed in two aspects. Firstly, the interfaces among columnar crystals and coarse equiaxed crystals or between the columnar crystals each other in the center of ingot are the regions of severe segregation, which deteriorate the hot workability and plasticity. On the other hand, severe dendritic segregations in the ingots result from long local solidification time and low temperature gradient in front of solid-liquid interface during solidification. In Russia ${ }^{[6]}$, the technologists proposed that the interfaces of columnar crystals and coarse equiaxed crystals or between the columnar crystals could be eliminated by the liquid metal cooling (LMC) directional solidification process. However, the conventional LMC directionally solidified technology

Received date: June 02,2015

Corresponding author: Li Fulin, Ph. D., High Temperature Material Division, Central Iron and Steel Research Institute, Beijing 100081, P. R. China, Tel: 0086-10-62182410, E-mail: lifulin1016@sina.com 
can not produce large size billets in industrial scale owing to these problems such as the carrying capacity of shell mold or contamination of liquid metal to equipment, segregation of elements because of progressive solidification of the mass melt, especially of the high cost. The grain refinement of $\mathrm{Ni}-\mathrm{Cr}-\mathrm{W}$ based superalloy can be obtained by near-liquidus, which can provide uniform alloy ingot and improve mechanical properties and hot workability ${ }^{[7]}$. However, commercial process on uniform fine grain casting technology demands further research.

Electro-slag remelting continuous directionally solidification (ESR-CDS) technology has been developed in CISRI (Central Iron and steel Research Institute, Beijing $)^{[8,9]}$. The ESR-CDS, a purity and low-cost remelting technology, can produce low-segregation directionally solidified ingots with large size (more than $\Phi 300 \mathrm{~mm}$ ). Rene88DT superalloy, typical second P/M alloy used for turbine disks, offers improved creep strength and fatigue crack growth resistance. The alloy is rather difficult to deform because of its poor workability, which is always processed through the powder metallurgy route. In the present paper, the casting structures of ESR-CDS Rene88DT alloy were characterized and an expression different from the ingot by conventional ESR or P/M was shown by SEM, EDS and so on. In addition, the inclusions in the billets by ESR-CDS, conventional ESR and P/M were analyzed statistically and the deformation plasticity was also compared. The objective of this paper is to focus on the ability of $\mathrm{C} \& \mathrm{~W}$ process for ESR-CDS alloy in order to avoid the expensive $\mathrm{P} / \mathrm{M}$ route.

\section{Experiment}

Rene88DT alloy, with a $\gamma^{\prime}$ volume fraction of about $40 \%$ (for the standard heat treatment), a low positive lattice mismatch $(0.05 \%)$ and a $\gamma^{\prime}$ phase solvus temperature at 1105 ${ }^{\circ} \mathrm{C}$, were manufactured by VIM (vacuum induction melting) and ESR-CDS. The bulk chemical composition (wt\%) of the studied Rene88DT alloy was $16.02 \mathrm{Cr}, 12.85 \mathrm{Co}, 3.96 \mathrm{Mo}$, 3.94W, 3.69Ti, 2.2Al, 0.76Nb, 0.038Zr, 0.015B, 0.05C and bal. Ni. Rene88DT alloy ingots with a diameter of $160 \mathrm{~mm}$ were fabricated by conventional ESR and ESR-CDS processes, The macrostructures of longitudinal sections of conventional ESR and ESR-CDS ingot were observed after grinding with $25 \mu \mathrm{m} \mathrm{SiC}$ paper, and subsequently etched using a solution consisting of $150 \mathrm{~g} \mathrm{CuSO}_{4}, 500 \mathrm{~mL} \mathrm{HCl}$ and $35 \mathrm{~mL} \mathrm{H}_{2} \mathrm{SO}_{4}$. The pinetree structures, element segregations and interdendritic precipitated phases of Rene88DT superalloy ingots produced by ESR and ESR-CDS were analyzed by JSM-6480LV type SEM and System SIS NSS300 type EDS. The carbides and borides phases were determined by selected area diffraction (SAD) patterns. In addition, microstructure evolutions of ESR and ESR-CDS samples after homogenizing heat treatment at $1200{ }^{\circ} \mathrm{C}$ for 12 and $24 \mathrm{~h}$ followed by furnace cooling (FC) were studied by SEM. Samples for SEM observation were ground with 10 $\mu \mathrm{m} \quad \mathrm{SiC}$ paper, polished with colloidal alumina and subsequently etched using Kallings etchant consisting of $5 \mathrm{~g}$ $\mathrm{CuCl}_{2}, 100 \mathrm{~mL} \mathrm{HCl}$ and $100 \mathrm{~mL}$ alcohol. The inclusions in Rene88DT alloys processed by ESR-CDS, conventional ESR and $\mathrm{P} / \mathrm{M}$ were analyzed and compared by statistical methods (100 fields of view magnified $\times 200$ ) with LEICA MEF4A picture analyzer. Finally, the hot deformation tests of Ren88DT alloys processed by different routes were conducted by MTS servo machine.

\section{Results and Discussion}

\subsection{Macrosegregation}

Eliminating macrosegregation of ingots is a critical factor for manufacturing wrought precipitation-hardened superalloys used at elevated temperature in highly stressed gas turbine rotor parts. P. Aubertin et al. ${ }^{[10]}$ have shown that the flow of solute-rich interdendritic liquid in the mushy zone during solidification is responsible for most types of observed macrosegregation such as freckles. The freckle defects are common in ESR-processed ingots because of deep molten pool with steeper sides, large mushy zones and enhanced local solidification times. There is intense mass flow of solute-rich liquid in the interdendritic region of the mushy zone. The freckle defects seem to be most likely at the mid-radius position, where the permeability of the mushy zone is greater than that at the centre of the ingot, and is deep enough to promote fluid flow though interdendritic channels.

The longitudinal macrostructure of Rene88DT ingot with $160 \mathrm{~mm}$ diameter obtained by conventional ESR is shown in Fig.1a. The large grain growth deviation (the angle between the grain growth direction and ingot longitudinal axis direction) indicates that a relatively deep pool profile and long mushy zone are presented during operation. Fig.1b shows a longitudinal macroetching of Rene88DT ingot processed by ESR-CDS.

During the conventional ESR process, the cooling rate is slowed down, opposing thermal and solute buoyancy forces lead to the remelting and the plume in the mushy zone, and then the formation of segregation channel. The deep V-shaped pool profile with a prolonged mushy zone can enhance the intensity of fluid flow in an ESR ingot, so the macrosegregation is more likely to be formed. In ESR-CDS process, the macrosegregation is effectively eliminated because of the shallow flat pool profile with a shorter and more uniformly distributed mushy zone. At the same time, the severe segregated region existing in the interfaces of columnar grains with different orientations in center of ESR ingot is eliminated by ESR-CDS process.

In addition, the columnar grain growth direction is parallel to the axis of ingot, which is <100> 
crystallographic orientation ${ }^{[8]}$. The oriented columnar grain boundaries avoid the maximum shear stress direction of $45^{\circ}$ to the axis of ingot during deformation, which greatly improves hot-workability. There are coarse equiaxed grains, interfaces of columnar grains with various orientations in the ingot prepared by conventional ESR, so its processability is obviously reduced. The direction of maximum shear stress is consistent with the slip crystallographic orientation of $\{111\}<110\rangle$ slip system during longitudinal compression, so the ESR-CDS ingots have a lower resistance of deformation and a higher plasticity than non-oriented ingots.

\subsection{Microsegregation}

During solidification, the superalloy ingots are prone to segregation of elements because of highly alloying. For dendritic solidification mode, the elements W, Co and Mo whose solute partition coefficients $(k)$ are more than 1 are enriched in the dendritic axis, while the $\gamma^{\prime}$ forming elements such as $\mathrm{Al}, \mathrm{Ti}, \mathrm{Nb}$ whose solute partition coefficients are smaller than $1\left(k<1=\right.$ in the interdendritic region ${ }^{[11,12]}$.

Fig.2 shows SEM images of the microstructures of conventional ESR and ESR-CDS Rene88DT superalloy ingots. As shown in the figures, darker area is the dendritic axis, while lighter-colored area is the interdendritic region. Fig.2a shows the microstructure of specimen conventional ESR, which exhibits chaotic dendrite growth directions, coarse dendrite arms and larger secondary dendrite arm

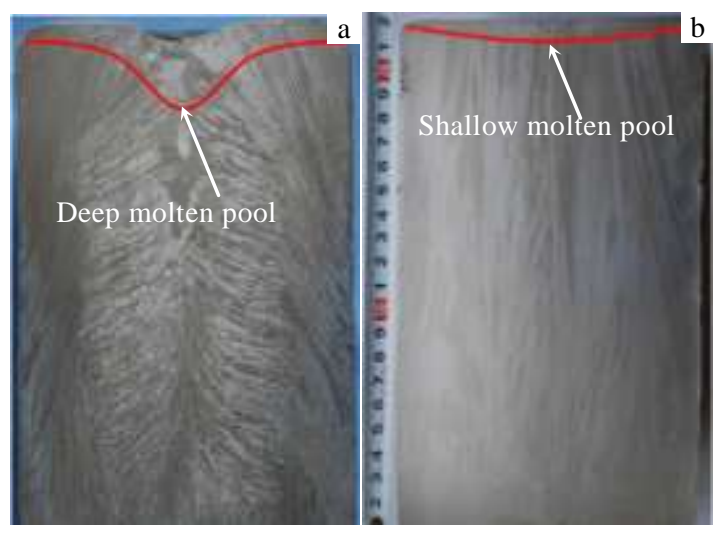

Fig.1 Macrostructures of the conventional ESR ingot (a) and ESR-CDS Rene88DT alloy ingot (b)

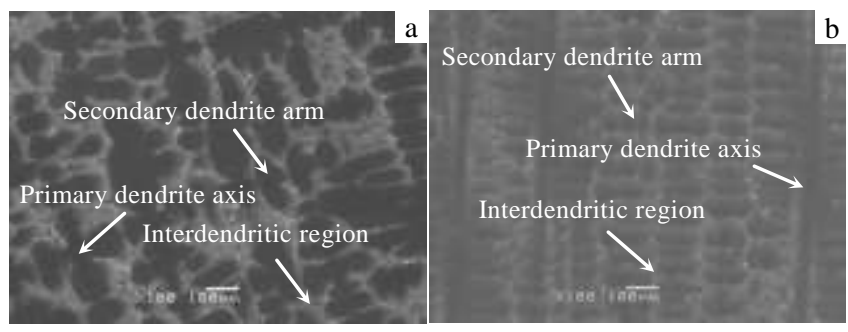

Fig.2 Dendritic structures of conventional ESR (a) and ESR-CDS (b) Rene88DT alloy ingots spacing (about $200 \mu \mathrm{m}$ ). Fig.2b reveals the microstructure of the ESR-CDS Rene88DT ingot. It can be seen that the primary dendrites are parallel to each other and secondary dendrite arms arrange in neat rows. The secondary dendrite arms bite each other, and the spacing is less than $100 \mu \mathrm{m}$. So the ESR-CDS Rene88DT ingot has a lower level of microsegregation than ESR one.

During the ESR processing, a deep V-shaped molten pool is formed, which influences the direction of crystal growth, the nonmetallic inclusion removal and the morphological characteristics of precipitated phases. There is a certain angle among the direction of temperature gradient perpendicular to the liquid-solid interface, which leads to a certain angle of the growth direction of primary dendritic axis. Closed mushy zone is bound to form because of crossing each other between the primary dendritic arms with different growth direction. Shallow flat-shaped molten pool is obtained during the ESR-CDS processing by controlling the direction of thermal flow, the temperature gradient of solidification front edge and the solidification rate. The growth direction of the primary dendritic axis is parallel to the axis of the ingot. Large size closed mushy zone is avoided because the dendrite arms are parallel to each other. In summary, the ESR-CDS processing greatly reduce the level of segregation and avoid fundamentally the formation of large-size interdendritic segregation phase and solidification shrinkage.

Fig. $3 \mathrm{a}$ and $3 \mathrm{~b}$ display $\gamma^{\prime}$ phase distributed in dendrite core and interdendritic area, respectively. The fine, spherical and dispersed $\gamma^{\prime}$ phase with average size of $80 \mathrm{~nm}$ spreads over the dendrite core. Interdendritic area presents butterfly-like $\gamma^{\prime}$ phase with an average size of $300 \mathrm{~nm} . \gamma+\gamma^{\prime}$ eutertic phase is distributed in the transition zone between the dendrite core and the interdendritic area, as shown in Fig.3c. It is clearly shown in Fig.3d that the phase in bright white colour is boride, while carbide appears as gray. It is notable that no $\eta-\mathrm{Ni}_{3} \mathrm{Ti}$ phase is detected in as-cast ESR-CDS sample.

Table 1 presents the compositions of alloying elements in the dendrite core and the interdendritic area. In comparison to bulk alloy composition, the interdendritic region is significantly enriched with $\mathrm{Ti}, \mathrm{Nb}$ and Mo. A segregation coefficient $k$ is defined as the ratio of the average concentration of the element in the dendrite cores to that in the interdendritic regions. The element partition to the interdendritic region is indicated by the value of $k$ less than 1 . While $k$ values greater than 1 indicate that the elements segregate to the dendrite cores.

The TEM images of carbide and boride phases in the ESR-CDS sample are shown in Fig.4, and the precipitated phases compositions determined by EDS are listed in Table 2. The data show that the carbide phase is significantly enriched with $\mathrm{Ti}$ and $\mathrm{Nb}$, and borides precipitate with high levels of $\mathrm{W}$ and Mo, and appreciate $\mathrm{Cr}$ level. It is well 

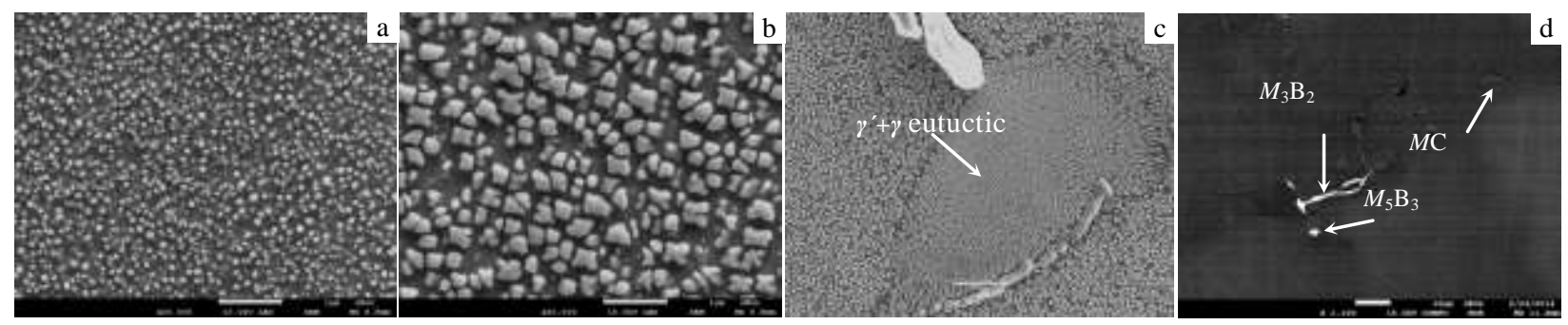

Fig.3 SEM images of precipitates in as-cast ESR-CDS Rene88DT alloy: (a) $\gamma^{\prime}$ phase in dendrite core, (b) $\gamma^{\prime}$ phase in interdendritic area, (c) $\gamma^{\prime}+\gamma$ eutectic phase, and (d) $M C$ type carbides, $M_{5} \mathrm{~B}_{3}$ and $M_{3} \mathrm{~B}_{2}$ type borides in interdendritic area

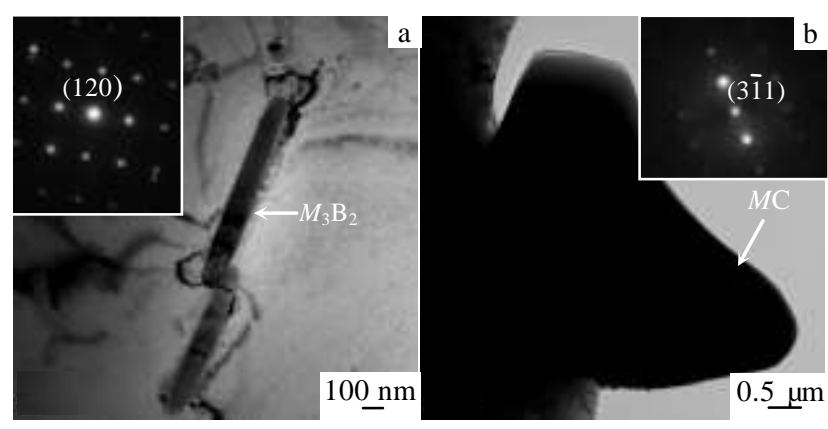

Fig.4 TEM images and corresponding selected area diffraction patterns of borides (a) and carbides (b) in ESR-CDS sample

known that $\mathrm{Nb}$ and $\mathrm{Ti}$ are strong carbide-formers and form the high stable carbide phase of the cubic type $M C$ with a wide homogeneity and complete mutual solubility. The appearance of the $M_{3} \mathrm{~B}_{2}$ boride in the investigated superalloy is confirmed by selected area diffraction patterns shown in Fig.4a.

Fig. 5 shows the microstructure of interdendritic region in conventional ESR specimen. The EDS analyses are listed in Table 3. It can be seen from Fig.5 and Table 3 that the interdendritic non-equilibrium precipitates in conventional ESR sample including lath-shaped $M C$ type carbides enriched in $\mathrm{Ti}$ and $\mathrm{Nb}, \gamma+\gamma^{\prime}$ eutectic phase, borides enriched in $\mathrm{Cr}$ and $\mathrm{Mo}$ and cellular $\eta-\mathrm{Ni}_{3} \mathrm{Ti}$ phase. Previous study revealed that center line segregation of $\eta-\mathrm{Ni}_{3} \mathrm{Ti}$ phase emerged in the conventional VAR (vacuum arc remelting) or ESR ingots, which was caused by macrosegregation and thus could not be homogenized. The elements such as $\mathrm{Ti}$ and $\mathrm{Nb}$ exhibit significant tendency to form segregation induced $\eta$ phase, and Rene88DT alloy could never be prepared by the ingot route in the eyes of some researchers ${ }^{[13]}$. The elements of $\mathrm{Ti}$ and $\mathrm{Nb}$ show smaller solute partition coefficients than other elements, which strongly segregate to interdendritic liquid during the final stage of solidification and form the interdendritic non-equilibrium precipitates enriched in $\mathrm{Ti}$ and $\mathrm{Nb}^{[14]}$. The type and morphology of interdendritic non-equilibrium precipitates depend on local solidification time, i.e. solidification rate. When the solidification rate is small, solute elements are enriched in a small amount of melt and precipitates such as $\eta-\mathrm{Ni}_{3} \mathrm{Ti}$ phase ${ }^{[15]}$ and large size carbides are formed.

\subsection{Homogenizing heat treatment}

The homogenizing treatment is the process of eliminating the microsegregation and non-equilibrium precipitates by high-temperature diffusion of elements ${ }^{[16]}$. The chosen homogenizing temperature for Rene88DT alloy is $1200{ }^{\circ} \mathrm{C}$. The holding time of homogenizing treatment depends on the time of non-equilibrium phase dissolving and segregation eliminating. Fig. 6 shows SEM images of the microstructure of ESR-CDS(Fig.6a, 6b) and conventional ESR(Fig.6c, 6d) specimens after homogenizing heat treatment at $1200{ }^{\circ} \mathrm{C}$ for $12 \mathrm{~h}$ (Fig.6a, 6c) and $1200^{\circ} \mathrm{C}$ for 24 h (Fig.6b, 6d) followed by furnace cooling. Slower cooling rate promotes the formation of $\gamma^{\prime}$ precipitates. According to Fig.6a, it is observed that the $\gamma+\gamma^{\prime}$ eutectic phase dissolves in ESR-CDS specimen after treatment at $1200{ }^{\circ} \mathrm{C}, 12 \mathrm{~h} \mathrm{FC}$, but dendritic segregation has not been completely eliminated, i.e. the composition of $\gamma^{\prime}$ forming elements such as $\mathrm{Al}, \mathrm{Ti}, \mathrm{Nb}$ is higher in the interdendritic region. Uniform distribution of elements is obtained in the ESR-CDS specimen after $1200{ }^{\circ} \mathrm{C}, 24 \mathrm{~h} \mathrm{FC}$ heat treatment (Fig.6b). As shown in Fig.6b, when subjected to $1200{ }^{\circ} \mathrm{C}$ for $12 \mathrm{~h}$ homogenizing heat treatment, the primary $\eta-\mathrm{Ni}_{3} \mathrm{Ti}$ phase is dissolved, but the forming elements Ti has no enough time to diffuse which leads to the formation of widmanstatten $\eta$ phase in the cooling process. When extending the holding time to $24 \mathrm{~h}$, the quantity of widmanstatten $\eta$ phase is substantially reduced, but there still exists obvious dendritic structure in the sample. In conclusion, the ESR-CDS process can significantly reduce the segregation of ingot and improve the density.

\subsection{Statistical results of inclusions}

Statistical results of the number and size of inclusions in Rene88DT alloy ingot produced by $\mathrm{P} / \mathrm{M}$ route, conventional ESR and ESR-CDS are listed in Table 4.The maximum size of inclusion is less than $5.89 \mu \mathrm{m}$ in ESR-CDS specimen, while there are inclusions larger than $10 \mu \mathrm{m}$ in ESR specimen and $\mathrm{P} / \mathrm{M}$ specimen. The more homogenizing 
Table 1 Compositions of alloy elements in dendrite core and interdendritic area and partition coefficients $(k)$

\begin{tabular}{ccccccccc}
\hline Element & $\mathrm{Al}$ & $\mathrm{Ti}$ & $\mathrm{Cr}$ & $\mathrm{Co}$ & $\mathrm{Ni}$ & $\mathrm{Nb}$ & $\mathrm{Mo}$ & $\mathrm{W}$ \\
\hline Dendrite core/wt\% & 1.85 & 2.66 & 16.37 & 13.59 & 56.57 & 0.42 & 3.65 & 4.83 \\
Interdendritic area/wt\% & 1.66 & 4.44 & 15.89 & 13.11 & 56.12 & 0.84 & 4.44 & 3.52 \\
$k$ & 1.11 & 0.60 & 1.03 & 1.04 & 1.01 & 0.5 & 0.82 & 1.37 \\
\hline
\end{tabular}

Table 2 Compositions of the precipitated phases in ESR-CDS sample by EDS (wt/\%)

\begin{tabular}{cccccccccc}
\hline Element & $\mathrm{C}$ & $\mathrm{B}$ & $\mathrm{Ti}$ & $\mathrm{Cr}$ & $\mathrm{Co}$ & $\mathrm{Ni}$ & $\mathrm{Nb}$ & $\mathrm{Mo}$ & $\mathrm{W}$ \\
\hline Precipitates $M \mathrm{C}$ & 13.37 & - & 35.19 & 1.13 & 0.61 & 2.27 & 23.34 & 9.25 & 13.42 \\
Precipitates $M_{5} \mathrm{~B}_{3}$ & - & 5.32 & 2.51 & 23.85 & 2.39 & 6.21 & 3.31 & 32.55 & 23.85 \\
Precipitates $M_{3} \mathrm{~B}_{2}$ & - & 7.88 & 3.6 & 27.34 & 3.7 & 7.54 & 3.7 & 31.42 & 14.83 \\
\hline
\end{tabular}

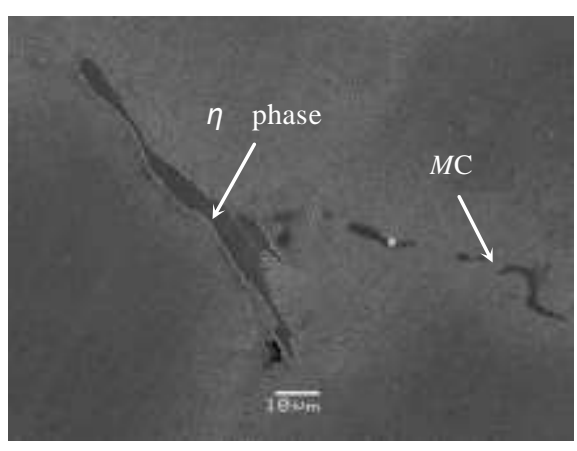

Fig.5 Non-equilibrium precipitates in conventional ESR sample

temperature fields of ESR-CDS process can effectively control and slow down the melt flowing, thereby high quality ingot being obtained. The stable melt pool and the parallel moving of solidification interface have the ability of removing the inclusions in ESR-CDS process.

\subsection{Improvement of hot working plasticity}

Increasing the hot working plasticity for the ESR-CDS Rene88DT alloy is intimately linked with the microstructure change that is associated with the low segregation and inclusion levels. Fig.7 shows the comparison of limited deformation of Rene88DT alloy produced by three different processes at subsolvus temperatures. Max permissive deformation of ESR-CDS alloy is over $70 \%$, and the max limited deformation of the $\mathrm{P} / \mathrm{M}$ and ESR Rene88DT alloy is below 50\%. Therefore, the effect of the decreasing of alloy segregation level induced by the control of directionally solidified alloy on increasing hot deformation plasticity is notable.

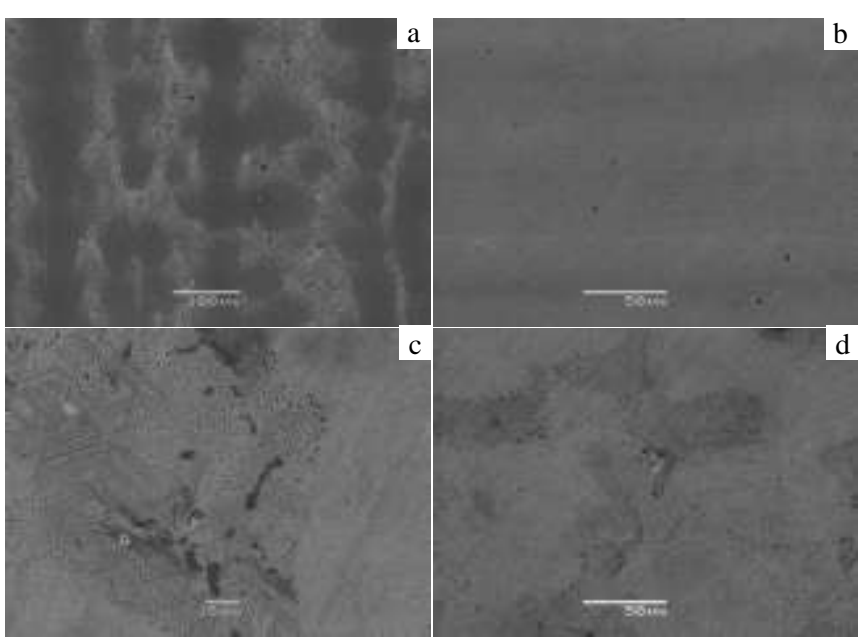

Fig.6 Microstructures of ESR-CDS ( $a, b)$ and conventional ESR (c, d) specimens after homogenizing heat treatment at $1200{ }^{\circ} \mathrm{C}$ for $12 \mathrm{~h}(\mathrm{a}, \mathrm{c})$ and $24 \mathrm{~h}(\mathrm{~b}, \mathrm{~d})$

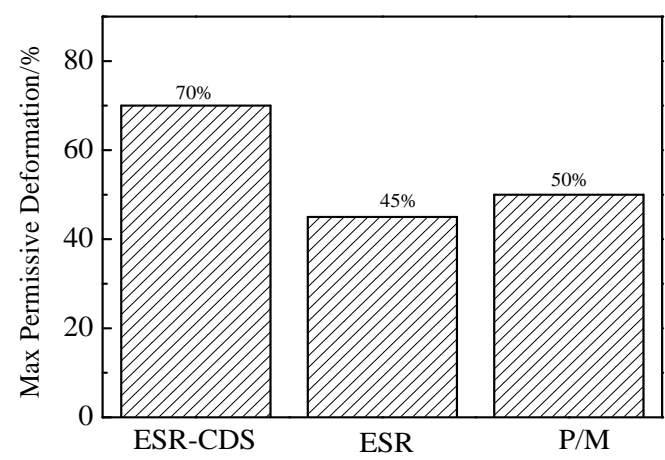

Fig.7 Comparision of max permissive deformation of Rene88DT alloy produced by three different processes

Table 3 Compositions of the precipitated phases in conventional ESR sample by EDS (wt/\%)

\begin{tabular}{cccccccccc}
\hline Element & $\mathrm{C}$ & $\mathrm{B}$ & $\mathrm{Ti}$ & $\mathrm{Cr}$ & $\mathrm{Co}$ & $\mathrm{Ni}$ & $\mathrm{Nb}$ & $\mathrm{Mo}$ & $\mathrm{W}$ \\
\hline$\eta$ phase & - & - & 14.56 & 3.40 & 10.30 & 67.70 & - & - & 2.00 \\
Precipitates $M \mathrm{C}$ & 16.12 & - & 35.07 & 2.28 & - & 5.18 & 23.45 & 8.45 & 9.4 \\
\hline
\end{tabular}


Li Fulin et al. / Rare Metal Materials and Engineering, 2016, 45(6): 1437-1442

Table 4 Statistical results of inclusions of Rene88DT produced by PM, ESR and ESR-CDS, respectively

\begin{tabular}{|c|c|c|c|c|c|c|c|c|c|c|}
\hline \multirow{2}{*}{ Process } & \multirow{2}{*}{$\begin{array}{c}\text { Area } \\
\text { percent } / \%\end{array}$} & \multicolumn{9}{|c|}{ The number of inclusions $/ 8.68 \mathrm{~mm}^{2}(100$ views of view magnified 200 times) } \\
\hline & & $\leqq 0.65$ & $0.65 \sim 1.31$ & $1.31 \sim 1.96$ & $1.96 \sim 2.62$ & $2.62 \sim 3.93$ & $3.93 \sim 5.89$ & $5.89 \sim 10$ & $\geqslant 10$ & Total \\
\hline $\mathrm{PM}$ & 0.013 & 92 & 128 & 57 & 29 & 31 & 20 & 5 & 1 & 363 \\
\hline ESR & 0.009 & 73 & 69 & 33 & 20 & 24 & 8 & 2 & 1 & 229 \\
\hline ESR-CDS & 0.004 & 19 & 43 & 26 & 12 & 6 & 1 & 0 & 0 & 107 \\
\hline
\end{tabular}

\section{Conclusions}

1) Directionally solidified Rene88DT superalloy ingot $(\Phi 160 \mathrm{~mm})$ can be prepared by electro-slag remelting continuous directional solidification (ESR-CDS) technology.

2) The ESR-CDS technology tends to eliminate the macro-segregation of ingot and improve hot workability, which is due to the shallow and flat molten pool during controlled directional solidification.

3) The ESR-CDS Rene88DT ingots exhibit lower levels of segregation than the conventional ESR ingots.

4) The uniform ESR-CDS ingot $(\Phi 160 \mathrm{~mm})$ can be obtained after homogenizing heat treatment at $1200{ }^{\circ} \mathrm{C}, 24 \mathrm{~h}$.

5) In the ESR-CDS Rene88DT ingot, the maximum size of inclusion is not more than $5.89 \mu \mathrm{m}$ and the inclusion volume numbers reduces by over $60 \%$ compared with both conventional ESR and $\mathrm{P} / \mathrm{M}$ ingots. Hot workability of ESR-CDS alloy can be improved.

\section{References}

1 Roger C Reed. The Superalloys Fundamentals and Applications $[\mathrm{M}]$. Cambridge: Cambridge University Press, 2006: 229

2 Chang D R, Krueger D D, Sprague R A. Superalloys 1984[C]. Pennsylvania: TMS, 1984: 245

3 Guo W M, Wu J T, Zhang F G et al. Journal of Iron and Steel Research, International[J], 2006, 13(5): 65

4 Krueger D D, Kissinger R D, Menzies R G. Superalloys 1992[C]. Pennsylvania: TMS, 1992: 277
5 Borofka J C, Tien J K, Kissinger R D. Powder Metallurgy and Oxide Dispersion Processing of Superalloys. In Tien J K, Caulfield $\mathrm{T}$ eds. Superalloys, Supercomposites and Superceramics[M]. San Diego: Academic Press, 1989: 237

6 Fu R. Research on Process and Technology of ESR-CDS[D]. Beijing: Iron and Steel Research Institute Postdoctoral Report, 2008: 21

7 Bai Kun, Hu Rui, Li Jinshan et al. Rare Metals Material and Engineering[J], 2014, 43(1): 1 (in Chinese)

8 Fu Rui, Chen Xichun, Ren Hao et al. Journal of Aeronautical Materials[J], 2011, 31(3): 8

9 Feng Di, Fu Rui, Chen Xichun et al. China Patent, 201010614036.0[P]. 2010

10 Aubertin P, Wang T, Cockcroft S L et al. Metallurgical and Materials Transactions[J], 2000, 31B: 801

11 Hu Min, Li Jinshan, Hu Rui et al. Rare Metals Material and Engineering[J], 2008, 37(5): 848 (in Chinese)

12 Pan Xiaolin, Sun Wenru, Li Zhan et al. Rare Metals Material and Engineering [J], 2010, 39(1): 55 (in Chinese)

13 Wlodek S T, Kelly M, Alden D A. Superalloys 1996[C]. Pennsylvania: TMS, 1996: 129

14 Min Z X, Shen J, Feng Z R et al. Acta Metallurgica Sinica $[\mathrm{J}]$, 2010, 46(12): 1543 (in Chinese)

15 Guo S R, Lu D Z. Acta Metallurgica Sinica[J], 1991, 27(6) A421 (in Chinese)

16 Guo Jianting. Materials Science and Engineering for Superalloys: Preparation Process[M]. Beijing: Science Press, 2008: 155 (in Chinese)

\title{
电渣重熔连续定向凝固 Rene88DT 合金组织与偏析行为
}

\author{
李福林, 付 锐, 冯 涤, 尹法杰, 田志凌 \\ (钢铁研究总院 高温材料研究所, 北京 100081)
}

\begin{abstract}
摘 要: 利用电渣重熔连续定向凝固技术(ESR-CDS)成功制备了Rene88DT高温合金铸锭。借助于金相显微镜, 带有能谱的扫描电镜以及 透射电镜, 对电渣重熔连续定向合金Rene88DT铸锭进行分析, 并与传统电渣铸锭进行了对比。研究结果显示, 电渣重熔连续定向凝固 合金Rene88DT铸锭消除了最为严重的中心偏析，中心偏析在传统电渣铸锭中是普遍存在的，这种偏析存在于柱状晶与等轴晶交界处或 者柱状晶之间相互交界面处。此外，电渣重熔连续定向凝固合金二次枝晶间距较传统电渣铸锭小，析出相尺寸也较小。由于微观偏析程 度的降低, 使得合金在经过 $1200{ }^{\circ} \mathrm{C}, 24 \mathrm{~h}$ 后的热处理即可达到均匀化效果。夹杂物统计结果显示，电渣重熔连续定向凝固合金夹杂物最 大尺寸为 $5.89 \mu \mathrm{m}$, 与传统电渣合金和粉末合金相比夹杂物数量降低 $60 \%$ 。电渣重熔连续定向凝固合金宏观偏析和夹杂物水平的降低可提 高热加工塑性, 为铸和锻工艺实施提供基础。

关键词：Rene88DT 合金; ESR-CDS 技术; 铸和锻工艺; 非平衡析出相; 夹杂物
\end{abstract}

作者简介: 李福林, 男, 1987 年生, 博士, 钢铁研究总院高温材料研究所, 北京 100081, 电话: 010-62182410, E-mail: lifulin1016@ sina.com 